\title{
Intravaginal Misoprostol versus Transcervical Foley Catheter for Pre-Induction Cervical Ripening and their Outcome - A Comparative Study
}

\author{
SABIHA NAZNEEN ${ }^{1}$, FERDOUSI SULTANA ${ }^{2}$, KAMRUN NAHAER ${ }^{3}$.
}

\begin{abstract}
:
Objective : To compare the efficacy of transcervical Foley Catheter and Intravaginal Misoprostol in pre-induction cervical ripening

Materials \& Methods : This crosssectional study was done in the inpatient dept. of obs. and gynae at the Rangpur Medical College and Hospital, Rangpur, Bangladesh between $1^{\text {st }}$ July 2005 to $30^{\text {th }}$ December, 2006. During 18 (eighteen) months of study period, 99 patients were enrolled, 50 were in group 1 where Misoprostol tablet was given vaginally and 49 were in group II where Foley Catheter was used transcervically. The Misoprostol tablet dosing regime was $50 \mu \mathrm{g}$ (one- fourth of a $200 \mu \mathrm{g}$ tablet), which was given vaginally (in the posterior vaginal fornix). The second dose was given after six hours. Though the maximum target was four doses that was $200 \mu \mathrm{g}$, cervical ripening took place in all the cases with only two doses. Cervical scoring was reassessed after four hours in both the groups.

Results: There were similar baseline characteristics such as age of the patients, socioeconomic condition etc. No significant difference was observed regarding parity, gravidity, gestational age, Bishop's score and pre-induction of labour. There was also no significant difference in the mean time of pre-induction to delivery interval, mode of delivery and neonatal out come. Change in Bishop's score was similar in both groups but more time was required from pre-induction to delivery in Foley catheter group. The most frequent complaint in Foley catheter group was mild discomfort at insertion. Vaginal delivery was higher in this group (63.3\%) whereas Caesarean section rate was higher in Misoprostol group (36\%) due to hyperstimulation syndrome.

Conclusion: Both intravaginal Misoprostol and transcervical Foley catheter have similar effectiveness as pre-induction agents in unripe cervix. Transcervical Foley catheter is associated with a lower incidence of hyperstimulation syndrome (presence of hypertonous utrine contraction associated with abnormal foetal heart rate) and higher incidence of vaginal deliveries.
\end{abstract}

Key words: Pre-induction, Misoprostol, Foley catheter, Cervical ripening.

\section{Introduction:}

Many women who undergo labor induction do not have a favorable cervix, which can lead to a prolonged and difficult induction, so some method of cervical ripening-pharmaceutical or mechanical-often is used $^{1,2}$. Pre- induction cervical ripening is often done to increase the likelihood of successful labour induction ${ }^{3-5}$ More than $15 \%$ of pregnant women need pre-induction cervical ripening before labour induction ${ }^{6}$. So there is a keen interest in developing safer, more cost effective and more efficient means of pre-induction cervical ripening.

Rates of labor induction in the United States rose from $9.5 \%$ to $23.2 \%$ of all deliveries between 1990 and $2010 .^{7,8}$ Although labor is usually induced for maternal or fetal indications, inductions without maternal or fetal indication, or elective inductions, recently have been on the rise $e^{9,10}$.

1. Junior Consultant Gynae \& Obst. Gangachara Health Complex, Rangpur.

2. Professor, Gynae \& Obst. Dpt. Rangpur Medical College.

3. Associate Professor, Gynae \& Obst. Dpt. Rangpur Medical College. 
There are few number of cervical ripening agents available. These include mechanical dilation and prostaglandin administration. Mechanical dilation was first described with laminaria, more recently, transcervical balloon catheter (Foley Catheter) has also been used successfully ${ }^{11,12}$.

The Foley catheter is inserted in order to change the cervical score, which has limited effect on uterine contractions. Insertion of Foley catheter into cervical canal and inflating the balloon with distilled water causes local release of prostaglandins due to compression.

Misoprostol acts as an exogenous pharmacological agent, which has an affect both on cervical ripening and uterine contractions. Seventeen cochrane review in 2001, comparing all forms of mechanical dilation with prostaglandins such as prostaglandin $E_{2}$ and prostaglandin $\mathrm{E}_{1}$ (Misoprostol), showed that both were effective as cervical ripening agent ${ }^{13,14}$. There is not much evidence in our country to assess the effectiveness of mechanical methods compared with prostaglandins in women with unripe cervices. The use of these methods, as compared with the use of prostaglandins, was associated with fewer episodes of excessive uterine contractions ${ }^{15}$. But use of prostaglandin showed higher incidences of caesarean section.

In this study two commonly used methods of cervical ripening were 1 . vaginal misoprostol and 2 . intracervical Foley catheter. The purpose of this study is to compare the effectiveness of vaginal misoprostol and intracervical Foley catheter for pre-induction cervical ripening.

\section{Methods:}

In this study 99 patients were selected by simple randomization- 50 in Misoprostol and 49 in group of Foley catheter. After taking written consents from patients or legal guardians, a questionnaire was used to collect information on age, occupation, income, chief complaints of the patients and history of past illness, menstrual and obstetric history. Demographic, socioeconomic and obstetric characteristics were matched to avoid significant difference between these two groups.

Those patients, who met the selection criteria, were explained the advantages and disadvantages of the procedures. The patients having history of hypersensitivity to misoprostol, cephalopelvic disproportion, multiple pregnancies, foetal distress, history of previous caesarean delivery, rupture membrane, history of asthma were excluded. The primary outcomes observed were number of doses required, time interval from start of pre-induction to delivery, the rates of normal delivery/caesarean section, and neonatal outcome. In recruited patients, a formal scoring of the cervix was done by Bishop's scoring system before pre-induction. The Misoprostol tablet dosing regime was $50 \mu \mathrm{g}$ (one- fourth of a $200 \mu \mathrm{g}$ tablet), which was given vaginally (in the posterior vaginal fornix). The doses were given after every six hours. Maximum target was four doses that was $200 \mu \mathrm{g}$. This study needed only two doses of Misoprostol for pre-induction cervical ripening.

Cervical scoring was reassessed after four hours. A Foley catheter size no. 16 was introduced through the cervix using a sterile technique .Once it has passed the internal os, $40 \mathrm{ml}$ distilled water was instilled into the balloon. The catheter was placed on traction by taping the end of the catheter to the inside of the patient's thigh. The procedure was considered to have failed if the catheter was in situ for 24 hours without a change in the Bishop's score.

Detailed information on delivery, such as date and time of insertion of Foley catheter or Misoprostol application, onset of labour pain, augmentation required or not, time taken for full dilatation-delivery were also recorded.

Collected data were compiled and necessary calculations, such as mean, standard deviation etc. and analysis such chi-square test, student's 't' test, correlation-coefficient test, etc. were done using a computer-based software Statistical Package for Social Science (SPSS). A P (Pearson's correlation coefficient) value $<0.05$ was considered as the minimum level of significance.

\section{Results:}

This study was designed to compare the efficacy of intracervical Foley catheter with vaginal Misoprostol in cervical ripening.

For cervical ripening only $1^{\text {st }}$ dose $(50 \mu \mathrm{g})$ was required in 32 patients (64\%) and a $2^{\text {nd }}$ dose needed in 18 patients (36\%). First dose was given at the time of admission and $2^{\text {nd }}$ dose was given after six hours of $1^{\text {st }}$ dose. This study needed only two doses of Misoprostol for pre-induction cervical ripening (Table-I). 
Table-I

Number of Misoprostol doses required for cervical ripening $(n=50)$

\begin{tabular}{lcc}
\hline Number of dose & No. of patients & $\%$ \\
\hline $1^{\text {st }}$ dose & 32 & 64 \\
$2^{\text {nd }}$ dose & 18 & 36 \\
\hline Total & 50 & 100 \\
\hline $1^{\text {st }}$ dose $=50 \mu \mathrm{g}$ & \\
$2^{\text {nd }}$ dose $=50 \mu \mathrm{g}$ & &
\end{tabular}

In Misoprpstol group (group 1) mean ( $\pm S D$ ) duration of onset of labour pain was $3.7 \pm 2.2$ hours, pre-induction to full dilatation was $8.9 \pm 3.8 \mathrm{hrs}$ and pre-induction to delivery interval was $9.2 \pm 4.1 \mathrm{hrs}$. In Foley catheter group (group II) duration of onset of labour pain was $7.3+3.0$ hours, pre-induction to full dilatation was $12.0 \pm$ $4.5 \mathrm{hrs}$, and pre-induction to delivery interval was 14.8 $\pm 5.2 \mathrm{hrs}$. The result of two groups were statistically significant $(\mathrm{P}<0.05)$. Time required was more for preinduction to full dilatation of cervices in Foley catheter group. In present study there is significant relationship $(r=-0.4927)$ between Bishop's score and pre-induction to full dilatation interval (Fig-1) in misoprostol group.

In this study 52 babies were delivered vaginally without any remarkable complications. Caesarean section rate was significantly higher $(p<0.05)$ in Misoprostol group whereas vaginal delivery was significantly higher in Foley catheter group $(\mathrm{P}<.038)$.

In Misoprostol group three patients developed hyperstimulation syndrome (presence of hypertonous uterine contraction associated with abnormal foetal heart rate) and emergency caesarean section was done for those patients.

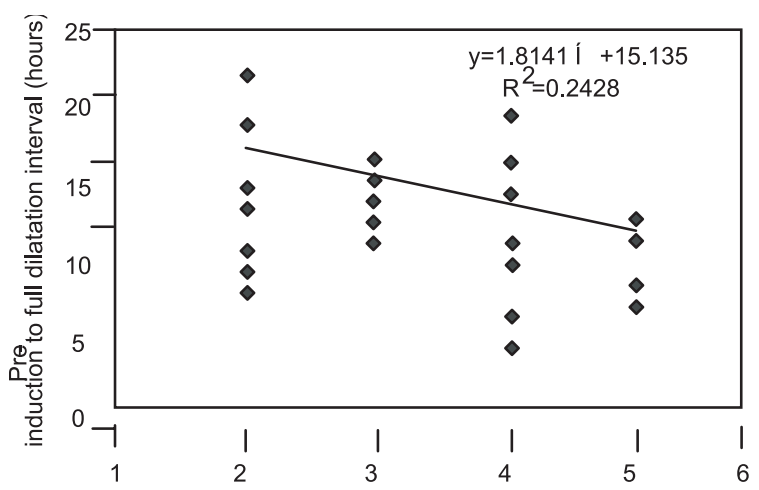

Fig-1: The scatter diagram shows significant relationship ( $r=-0.4927)$ between Bishop's score and pre-induction to full dilatation interval (hours) in group I $(n=50)$.

Comparison of augmentations between two groups showed that use of oxytocin and artificial rupture of membrane (ARM) was higher in Foley catheter group (Table-II).

Any change of cervical scoring in Misoprostol group and Foley Catheter group was compared. In Foley catheter group higher pre-induction to full dilatation interval time was observed. In addition results of both the groups in terms of cervical ripening, pre-induction to delivery interval, neonatal outcomes were similar. But vaginal delivery was higher in Foley catheter group.

The above table shows that $1^{\text {st }}$ dose of Misoprostol was required for cervical ripening in 32 (64\%) cases where $1^{\text {st }}$ dose was given at the time of admission and $2^{\text {nd }}$ dose was given after 6 hours of $1^{\text {st }}$ dose.

Table-II

Comparison of augmentations between two groups ( $n=99)$

\begin{tabular}{|c|c|c|c|c|c|c|c|}
\hline \multirow[t]{2}{*}{ Indications } & \multicolumn{2}{|c|}{ Group I $(n=50)$} & \multicolumn{2}{|c|}{ Group II $(n=49)$} & \multirow[t]{2}{*}{ Chi Value } & \multirow[t]{2}{*}{$\mathrm{df}$} & \multirow[t]{2}{*}{ Pvalue } \\
\hline & $\mathrm{n}$ & $\%$ & $\mathrm{n}$ & $\%$ & & & \\
\hline Oxytocin drip & 4 & 8.0 & 0 & 0.0 & 2.28 & 1 & $0.061^{\mathrm{ns}}$ \\
\hline ARM & 18 & 36.0 & 14 & 28.6 & 0.16 & 1 & \\
\hline ARM+Oxytocin drip & 11 & 22.0 & 30 & 61.2 & 15.69 & 1 & \\
\hline None & 17 & 34.0 & 5 & 10.2 & 8.11 & 1 & \\
\hline
\end{tabular}

$0.691^{\text {ns }} 0.001^{\text {ns }} 0.004^{\text {ns }}$

Group I: Misoprostol

Group II: Foley catheter

$\mathrm{S}=$ Significant, $\mathrm{ns}=$ not significant

$P$ value considered significant $p<0.05$ 
Mode of delivery in Table-III shows that 52 babies were delivered vaginally without any remarkable complications. Caesarean section was significantly higher $(p<0.05)$ in group I compared to group II. Vaginal delivery was significantly higher in Foley catheter group.

Correlation between Bishop's score and preinduction to full dilatation interval (hours) in group I $(n=50)$

The Bishop's score of 50 cases was expressed in score and pre-induction to full dilatation interval was measured in hours. A significant negative correlation was found between Bishop score and pre-induction to full dilatation interval.

The value of $\pi$ was -0.4927 and it is significant $(p<0.05)$. Increase in Bishop's score reduces the pre-induction to full dilatation interval. Therefore, there was linear negative association between Bishop score and pre-induction to full dilatation interval (hours) in group I.

\section{Correlation between Bishop's score and pre- induction to full dilatation interval (hours) in group II $(n=49)$}

The Bishop's score of 49 cases was expressed in score and the pre-induction to full dilatation interval was measured in hours. A significant negative correlation was found between Bishop's score and pre-induction to full dilatation interval.

The value of $\pi$ was -0.6295 and it is significant $(p<0.05)$. Increase in Bishop's score reduces the pre-induction to full dilatation interval. Therefore, there was linear negative association between Bishop's score and pre-induction to full dilatation interval (hours) in group II.

Table-V: Shows first minute Apgar was 8, five min Apgar was 9, and the rate of meconium stained amniotic fluid was $10 \%$. In second group, first min Apgar was 8, five min Apgar was 9, \& the rate of meconium stained amniotic fluid was $5 \%$. None of the neonate had any feature suggestive of meconium aspiration.

Table-III

Comparison of mode of delivery between two groups ( $n=99$ )

\begin{tabular}{lccccccc}
\hline Indications & \multicolumn{2}{c}{ Group I $(\mathrm{n}=50)$} & \multicolumn{2}{c}{ Group II $(\mathrm{n}=49)$} & ChiValue & $\mathrm{df}$ & $\mathrm{P}$ value \\
& $\mathrm{n}$ & $\%$ & $\mathrm{n}$ & $\%$ & & & \\
\hline Vaginal & 21 & 42.0 & 31 & 63.3 & 4.49 & 1 & $0.034^{\text {stq }}$ \\
Forceps & 7 & 14.0 & 10 & 20.4 & 0.71 & 1 & $0.398^{\text {ns }}$ \\
Ventouse & 4 & 8.0 & 3 & 6.1 & 0.13 & 1 & $0.511^{\text {ns }}$ \\
Caesarean Section & 18 & 36.0 & 5 & 10.2 & 9.33 & 1 & $0.002^{\mathrm{s}}$ \\
\hline
\end{tabular}

Group I: Misoprostol

Group II: Foley Catheter

$\mathrm{S}=$ Significant, $\mathrm{nS}=$ not significant

$P$ value considered significant $p<0.05$

Table-IV

Comparison of intrapartum variables between group I and II ( $n=99)$

\begin{tabular}{lccccc}
\hline Indications & $\begin{array}{c}\text { Group I(n=50) } \\
\text { Mean } \pm \text { SD }\end{array}$ & $\begin{array}{c}\text { Group II(n=49) } \\
\text { Mean } \pm \text { SD }\end{array}$ & tValue & df & P value \\
\hline Pre-induction to labour & $3.7 \pm 2.2$ & $7.3 \pm 3.0$ & 6.74 & 97 & $0.001^{\mathrm{s}}$ \\
Pain interval (hours) & & & & & \\
Pre-induction to full Dilatation interval (hours) & $8.9 \pm 3.8$ & $12.0 \pm 4.5$ & 3.11 & 97 & $0.003^{\mathrm{s}}$ \\
Pre-induction to delivery interval (hours) & $9.2 \pm 4.1$ & $14.8 \pm 5.2$ & 5.80 & 97 & $0.001^{\mathrm{s}}$ \\
\hline
\end{tabular}

Group I: Misoprostol

Group II: Foley Catheter

$\mathrm{S}=$ Significant, ns=not significant,

$P$ value considered significant $p<0.05$ 


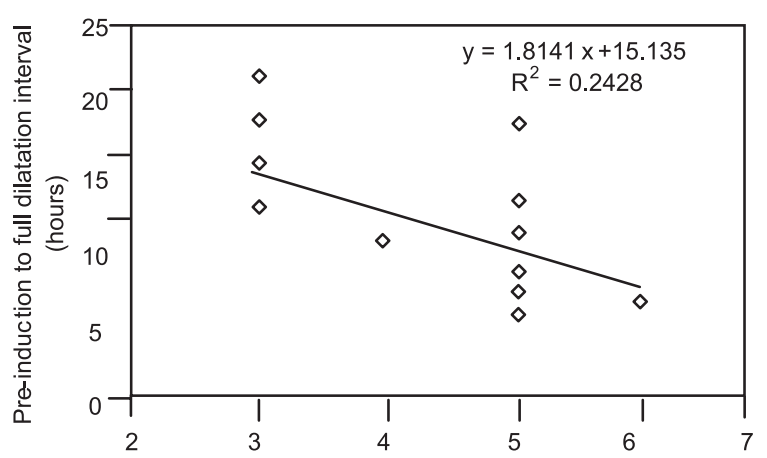

Fig-2: The scatter diagram shows significant relationship ( $r=-0.6295)$ between Bishop's score and pre- Induction to full dilatation interval (hours) in group II ( $n=49)$.

Table-V

Neonatal out comes in the studied groups

\begin{tabular}{lccc}
\hline Groups & \multicolumn{2}{c}{ Mean \pm Standard deviation } & \\
\cline { 2 - 3 } & $\begin{array}{c}\text { Misoprostol } \\
\text { Group }\end{array}$ & $\begin{array}{c}\text { Foley } \\
\text { Catheter } \\
\text { Group }\end{array}$ & $\begin{array}{c}\mathrm{P} \\
\text { Value }\end{array}$ \\
\hline 15t min Apgar & 8 & 8 & 1 \\
Five min Apgar & 9 & 9 & 1 \\
Meconium stained & $5(10 \%)$ & $3(5 \%)$ & $>0.1$ \\
Amniotic Fluid & & & \\
\hline
\end{tabular}

\section{Discussion:}

Induction of labour before the cervix is favourable often results in prolonged labour with subsequent delivery by caesarean section. Therefore iatrogenic ripening of the unfavourable cervix should shorten labour and lead to a higher incidence of successful induction.

In present study 99 patients were selected by simple randomization, 50 in misoprostol group and 49 in Foley's catheter group.

The results from this small study showed that an inflated Foley's catheter placed in the extra amniotic space was as efficient as intravaginal misoprostol tablet for ripening the unfavourable cervix. The Foley's catheter was acceptable to the patients as the misoprostol tablet. There was no accidental rupture of membrane, antepartum or postpartum pyrexia for insertion of Foley's catheter group.

In this study in misoprostol group( $n=50)$, first dose of misoprostol tablet $(50 \mathrm{mcg})$ was required in 32 patient $(64 \%)$ and $2^{\text {nd }}$ dose required in 18 patient (36\%). The two studies showed good results with a dose of misoprostol lower than 200 $\mu$ g given vaginally ${ }^{16,17}$.

Induction to delivery interval was $(9.2 \pm 4.1 \mathrm{hr}$.), showed statistically significant difference $(P<0.001)$. Saleem $\mathrm{S}^{18}$ had showed induction to delivery time more than $12 \mathrm{hr}$. in misoprostol group.

A comparative study of induction of labour by Foley's catheter with that by sweeping of the membrane in prolonged pregnancy by Dewan ${ }^{19}$ showed induction of labour by Foley's catheter in especially postdated pregnancies with very unripe cervix. It had been found to result in a safe vaginal delivery with short induction to delivery interval in Foley's group with $40 \mathrm{ml}$ balloon. Higher proportion of Vaginal delivery was achieved in $60 \mathrm{ml}$ Foley balloon group compared to $30 \mathrm{ml}$ Foley balloon group ${ }^{20}$. The $60-\mathrm{mL}$ balloon was more likely to result in delivery within 12 hours $^{21}$.

Where as present study showed induction to delivery interval, more time was required in Foley's catheter group $(14.8 \pm 5.2 \mathrm{hr}$.)

Oxytocin use was more common during labor in women who had started out with transcervical Foley balloons than in those who started with prostaglandins (RR 1.51, 95\% Cl, 1.15-1.97). ${ }^{5}$ In this study oxytocin use along with ARM was more $63 \%$ in group II in comparison to $42 \%$ in group I.

The present study showed that there was a negative correlation between bishop's score and time of full dilatation of cervix which was significant difference, in Foley's catheter group more time was required $(14.8 \pm 5.5 \mathrm{hr})$. In compare to Ferdous $\mathrm{J}^{22}$ shows no significant difference between two groups where misoprostol group requires $(21.18 \pm 2.32 \mathrm{hr})$.

The number of caesarean section was $18(36 \%)$ in misoprostol group, and 5 (10.2\%) in Foley's catheter group. In similar type of study Ferdous $\mathrm{J}^{22}$ showed that number of caesarean section was $9(20 \%)$ in misoprostol group and 8(17.3\%) in Foley's catheter group, statistically there was no significant difference. Rozenberg ${ }^{23}$ demostrated that the rate of caesarean section performed for acute fetal distress was higher in misoprostol group.

In this study there was no statistically significant difference in neonatal outcome. None of neonate had any feature suggestive of meconium aspiration.

Results of both groups, in terms of cervical ripening, induction to delivery interval, fetal outcome was 
similar. Vaginal delivery was higher in Foley's catheter group in this study. Considering requirement of proper monitoring of mother and fetus, lack of adequate facilities in peripheral hospitals in Bangladesh, it is beneficial to use Foley's catheter than misoprostol.

\section{Conclusion:}

Both intravaginal Misoprostol and transcervical Foley catheter have similar effectiveness as pre-induction agents in unripe cervix. Transcervical Foley Catheter is associated with a lower incidence of hyperstimulation syndrome and higher incidence of vaginal deliveries in comparison to intravaginal Misoprostol.

\section{References:}

1. Jozwiak M, Bloemenkamp KWM, Kelly AJ, Mol BWJ, Irion O, Boulvain M. Mechanical methods for induction of labor. Cochrane Database of Systematic Reviews. 2012, Issue 3.

2. Boulvain M, Kelly A, Lohse C, Stan C, Irion O. Mechanical methods for induction of labour. Cochrane Database of Systematic Reviews. 2001, Issue 4.

3. Bishop EH. Pelvic scoring for elective induction. Obstet Gynecol 1964; 24:266-8.

4. Garnet WJ. Prognostic signs of surgical induction of labour Med J Aust 1960; 47:92931.

5. Brindley BA, SOKOL RJ. Induction and augmentation of labour: Basis and methods for current practice. Obstet Gyecol Surv 1988; 43:730-3.

6. Wing DA. Labour induction with misoprostol. AmJ obstet Gynecol 1999; 181:-45.

7. Martin JA, Hamilton BE, Ventura SJ, Osterman MJK, Wilson EC, Mathews TJ. Births: Final Data for 2010. National Vital Statistics Reports. 2012;61(1).

8. Caughey AB, Sundaram V, Kaimal AJ, et al. Maternaland Neonatal Outcomes of Elective Induction of Labor. Evidence Report/Technology Assessment No. 176. AHRQ Publication No. 09E005. Agency for Healthcare Research and Quality. March 2009.
9. Fisch JM, English D, Pedaline S, Brooks K, Simhan HN. Labor induction process improvement: a patient quality-of-care initiative. Obstet Gynecol. 2009;113(4):797-803.

10. Zhang J, Yancey MK, Henderson CE. US national trends in labor induction, 1989-1998. J Reprod Med. 2002;47:120-124.

11. Embrey MP, Mollison BC. The unfavorable cervix and the induction of labor using a cervical balloon. J obster gynaecol Br Commonw 1967;74:44-8.

12. Gelber S, Sciscone A. Mechanical methods of cervical ripening and labor induction, Clin Obstet Gynecol 2006; 49:642-57.

13. J, Thomas J. Vaginal prostaglandin (PGE2 and PGF2a) for induction of labour at term. Cochrane Database Syst Rev 2003; 4.

14. Hofmeyr GJ, Gulmezoglu AM. Vaginal Misoprostol for cervical ripening and induction of labor, Cochrane Database Syst Rev 2001; 4.

15. Prager M, Eneroth Grimfors E, Edlund M, Marions L. A randomised controlled trial of intravaginal dinoprostone, intravaginal misoprostol and transcervical balloon catheter for labour induction. BJOG. 2008; 115: 14431450

16. Preutthipan S, Herabutya Y. A randomized comparison ovaginal misoprostol and dinoprostone for cervical priming in nulliparous women before operative hysteroscopy. Fertil Steril 2006;86(4):990-4.

17. Choksuchat C, Cheewadhanaraks S, Getpook C, Wootipoom V,Dhanavoravibul K. Misoprostol for cervical ripening in non-pregnant women: a randomized double-blind controlled trial oforal versus vaginal regimens. Hum Reprod 2006;21(8):2167-70.

18. Saleem S. Efficacy of Dinoprostone, Intracervical foley's and misoprostol in labour induction. J coll Physicians Surg Pak. 2006; 16(4): 276-9.

19. Dewan F, Begum R, Chowdhury SB. Comparative study of induction of labor by catheter with that of sweeping of the membrane 
in prolonged pregnancy. Sir Salimullah Medical College J 1995; 3:22-7

20. Wijepala J. COMPARISON OF 30 ML AND 60 ML FOLE CATHETER FOR CERVICAL RIPENING. European Scientific Journal 2013 9(6): 1857-7881.

21. Delaney S, Shaffer BL, Cheng YW, et al. Labor induction with a Foley balloon inflated to $30 \mathrm{~mL}$ compared with $60 \mathrm{~mL}$ : a randomized controlled trial. Obstet Gynecol. 2010;115(6):1239-1245.
22. Ferdous J. A randomized clinical trial to compare the efficacy and effectiveness of misoprostol tablet and Foley's catheter on cervical ripening, in Dhaka medical college hospital 2003;48-50

23. Rozenbergp,chevert,Goffinet F,Durand-Zaleski I, Ville $Y$,Vayssiere $c$, et al.Induction of labour with a viable infant; a randomized clinical trial comparing intravaginal misoprostol and intravaginal dinoprostol BJOG2001;108; 1255-62. 